\title{
The Impact of Chemotherapy on the Ovaries: Molecular Aspects and the Prevention of Ovarian Damage
}

\author{
Charlotte Sonigo ${ }^{1,2}{ }^{-}$, Isabelle Beau ${ }^{2}$, Nadine Binart ${ }^{2}$ and Michaël Grynberg ${ }^{1,2,3, *}$ \\ 1 Department of Reproductive Medicine and Fertility Preservation, Hôpital Antoine Béclère, 92140 Clamart, \\ France; charlotte.sonigo@aphp.fr \\ 2 Inserm U1185 Université Paris-Sud, Université Paris Saclay, 94276 Le Kremlin Bicêtre, France; \\ isabelle.beau@u-psud.fr (I.B.); nadine.binart@inserm.fr (N.B.) \\ 3 Inserm U1133 Université Paris Diderot, 75013 Paris, France \\ * Correspondence: michael.grynberg@aphp.fr; Tel.: +33-14-537-4053; Fax: +33-14-537-4980
}

Received: 11 October 2019; Accepted: 24 October 2019; Published: 27 October 2019

\begin{abstract}
Cancer treatment, such as chemotherapy, induces early ovarian follicular depletion and subsequent infertility. In order to protect gametes from the gonadotoxic effects of chemotherapy, several fertility preservation techniques—such as oocyte or embryo cryopreservation with or without ovarian stimulation, or cryopreservation of the ovarian cortex-should be considered. However, these methods may be difficult to perform, and the future use of cryopreserved germ cells remains uncertain. Therefore, improving the methods currently available and developing new strategies to preserve fertility represent major challenges in the area of oncofertility. Animal and ovarian culture models have been used to decipher the effects of different cytotoxic agents on ovarian function and several theories regarding chemotherapy gonadotoxicity have been raised. For example, cytotoxic agents might (i) have a direct detrimental effect on the DNA of primordial follicles constituting the ovarian reserve and induce apoptosis; (ii) induce a massive growth of dormant follicles, which are then destroyed; or (ii) induce vascular ovarian damage. Thanks to improvements in the understanding of the mechanisms involved, a large number of studies have been carried out to develop molecules limiting the negative impact of chemotherapy on the ovaries.
\end{abstract}

Keywords: fertility preservation; ovaries; burnout effect

\section{Introduction}

In the past few decades, the significant diagnostic and therapeutic progress made in the field of oncology has improved the survival rates of children and young adults. However, it is now clearly established that these excellent results are achieved through treatments that have potentially deleterious impacts on reproductive function. In order to protect gametes from the gonadotoxic effects of chemotherapy and/or radiotherapy, several fertility preservation (FP) techniques, such as oocyte or embryo cryopreservation with or without ovarian stimulation or cryopreservation of the ovarian cortex, should be proposed [1]. However, the application of these methods may be limited by age, pubertal status, disease, and emergency. In addition, these procedures may be difficult to perform, and the future use of cryopreserved germ cells remains uncertain. Therefore, improving the FP methods currently available and developing new FP strategies represent major challenges in oncofertility.

Chemotherapy exerts toxicity on the ovaries directly. It is important to distinguish between the short- and long-term effects of drugs on the ovaries. Soon after the beginning of treatment, chemotherapy induces apoptosis of growing follicles, leading to temporary amenorrhea. The impact of drugs on fertility after healing concerns the effects of chemotherapy on the primordial follicular reserve 
as these treatments may lead to a premature loss and, at worst, primary ovarian insufficiency (POI). POI is a well-known long-term side effect of cancer chemotherapy treatment. The extent of ovarian damage depends upon several factors, of which the most important are the type of drug, its dosage, and the protocol [2]. Chemotherapeutic agents can be divided into five categories: alkylating agents, antitumor antibiotics, platinum-based drugs, antimetabolites, and taxanes. The mechanisms implicated in the gonadotoxicity of these molecules have been explored in various experimental models, such as analysis of histological female ovary sections after chemotherapy, animal models treated with injections, xenograft models, or cell cultures in the presence of active metabolites of chemical agents, and are not yet fully understood [3]. Several hypotheses have been proposed and could coexist. On the one hand, chemotherapeutic agents could exert direct toxicity on primordial follicles, inducing DNA damage and subsequent apoptosis. On the other hand, it has been suggested that these drugs could trigger an indirect depletion of primordial follicles by over-recruitment. Increasing knowledge of the possible mechanisms implicated in chemotherapy-induced ovarian damage will facilitate the development of new therapies, called fertoprotective agents [4], aimed at protecting the follicular reserve [5].

\section{Follicular Ovarian Reserve and Its Regulation}

In mammals, the follicular ovarian reserve, constituted by primordial follicles, is established early on in life then keeps declining regularly throughout the reproductive period. The pool of primordial follicles serves as a source of growing follicles and fertilizable eggs for the entire female reproductive life. Actually, each primordial follicle can remain quiescent for years; be activated and enter the growing process; or undergo atresia directly from the dormant stage [6]. To produce mature oocytes, activated primordial follicles develop through primary and secondary stages before acquiring an antral cavity. At the antral stage, most follicles undergo apoptotic degeneration and only a few of them grow further to reach the preovulatory stage under the cyclic gonadotropin stimulation that occurs after puberty [7].

The maintenance of female reproductive function implies the presence of a vast majority of quiescent primordial follicles and continuous repression of primordial follicle activation into early growing follicles. This activation, starting during fetal life, is finely controlled though maintaining a balance between inhibitory and stimulatory factors. In vitro experiments and genetically modified mouse or sheep models have enabled the decoding of the molecular mechanisms that control follicular activation. Numerous factors, such as growth factors, hormones, transcription factors, or cytokines, produced by oocytes and/or granulosa cells, can act in an autocrine, paracrine, or endocrine manner [8]. The quiescence of primordial follicles is maintained by several molecules including phosphatase and tensin homolog deleted on chromosome 10 (Pten), tuberous sclerosis complexes 1-2 (Tsc1-Tsc2) complex, Forkhead box protein O3A (Foxo3A), p27, anti-Müllerian hormone (AMH), and Forkhead box L2 (FoxL2) [6]. Many studies have highlighted the crucial roles of the phosphatidyl-inositol-3-kinase (PI3K) signaling pathway in oocytes in controlling follicular activation [9]. Indeed, in genetically modified mouse models, it was observed that the PI3K-Akt-mammalian target of rapamycin (mTOR) signaling pathway is crucial for the control of survival and activation of primordial follicles [10]. For example, Pten and Tsc1-2 are negative regulators of this signaling pathway and, in mice, the deletion of these genes from oocytes leads to primordial follicle activation and subsequent early follicular depletion. In these models, mTOR activity is accelerated within the oocyte, highlighting the critical role of this serine/threonine kinase in primordial follicle activation. The transcription factor FoxO3A, mainly expressed in the oocytes of resting follicles, acts downstream of the PI3K signaling pathway and appears to be the main actor involved in follicular activation [8]. At the same time, the survival of primordial follicles is maintained by other mechanisms involving PDK1 signaling, rpS6. Several studies have suggested the involvement of the autophagy process in the regulation of the ovarian reserve of primordial follicles. For example, autophagy is implicated in maintaining the primordial oocyte pool in murine newborns [11], and the induction of autophagy at birth seems to be a crucial step to preserve the stock of primordial follicles [12,13]. 
In the same manner, primordial follicle survival or apoptosis results from a balance between the expression of survival (antiapoptotic) and proapoptotic factors. Among these factors, the proteins B-cell lymphoma 2 (Bcl-2) and Bcl-2-associated X protein (BAX) likely play a critical role.

Thus, a synergistic and coordinated suppression of follicular activation, provided by multiple inhibitory and activator molecules, is necessary to preserve the primordial follicular stockpile in association with the process maintaining dormancy. Any disorder in these complex mechanisms can lead to a premature loss of the follicular reserve [14].

\section{Follicular Atresia and Apoptosis}

\subsection{Pathophysiology: DNA Alteration, Follicular Atresia, and Apoptosis}

The molecules used in chemotherapy induce alterations in the DNA. Double-stranded breaks (DSB) are one of the main DNA lesions caused by these cytotoxic agents and the most severe. DSB can, in turn, lead to either DNA repair pathways allowing cell survival or cell death by apoptosis [15]. DNA repair pathways differ according to the type of chemotherapeutic agent and may involve, for example, pATM, RAD51, or PARP1 proteins [15]. When the repair pathways are not sufficiently activated, DNA damage induces cellular apoptosis. This mechanism is mainly mediated by p63 protein (and, more specifically, the TAp63 isoform), which activates Bcl2-associated X (BAX) protein and the Bcl-2 antagonist killer (BAK) protein. BAX/BAK activation can be transmitted by TAp73 or secondary to p53 up-modulator of apoptosis) and phorbol-12-myristate-13-acetate-induced protein 1 activation [16]. These mechanisms are particularly complex within the ovaries and differ according to the type of chemotherapy molecule. A recent and extensive review discusses the induction and repair of DNA damage in the ovaries [15].

The impact of chemotherapeutic agents on growing follicles is well known, and apoptotic pathways have been well documented [5,17]. Almost all classes of drugs induce DNA alteration of granulosa cells and/or oocytes, leading to either apoptosis of growing follicles or the survival of mutagenic oocytes. This phenomenon often induces temporary amenorrhea [18]. More rarely, if fertilization occurs during drugs' exposure, it can lead to spontaneous abortion or congenital abnormalities in the offspring [19]. These complications are closely related to the timing of oocyte exposure to cytotoxic treatment. Fertilization months or years after the end of protocol seems to be safe for offspring as these pregnancies are achieved from oocytes exposed in a dormant state, which remained genetically undamaged [20].

While apoptosis and atresia in growing follicles in response to chemotherapeutic agents have been well investigated, the nature of these mechanisms in dormant follicles is still under debate [15]. According to several studies, the main chemotherapeutic agents induce follicular depletion by directly affecting the primordial follicles entering massively into atresia [15]. Overall, rodent models as well as models of human ovarian xenograft or in vitro ovary cultures were used to investigate the impact of chemotherapy on primordial follicles. Cyclophosphamide is a widely used alkylating agent and is recognized as one of the most gonadotoxic drugs. It has been shown to induce DNA double-stranded breaks and activate the DNA damage response in a human ovarian xenograft model [21]. These results were confirmed in in vitro ovarian cultures with cyclophosphamide active metabolite [22-24] or after in vivo cyclophosphamide injection [25]. In the same manner, in vitro analysis of newborn mouse ovaries revealed DNA damage and apoptosis of primordial follicles after cisplatin treatment [26,27], which were further confirmed after in vivo injection in newborn or adult mice $[16,25]$. Recently, a model of a xenograft of human cortex ovaries in nude mice revealed the same results [28]. Furthermore, similar effects with similar models were also found following doxorubicin exposure [29,30].

The improvement of knowledge of the specific apoptotic and DNA repair pathways involved in the ovarian damage induced by chemotherapy will reveal targets for protective agents to reduce or prevent ovarian damage (Figure 1) [3]. 


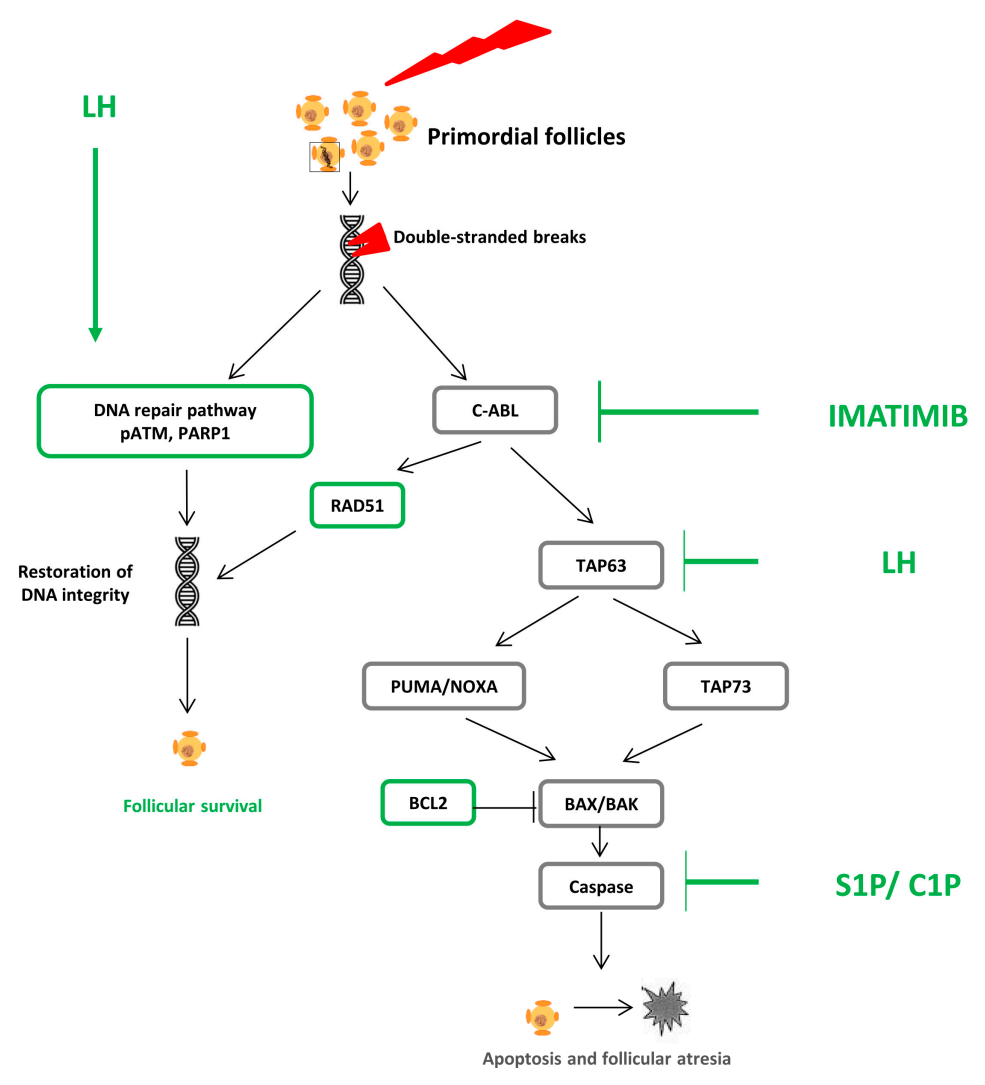

Figure 1. First hypothesis of chemotherapy-induced ovarian damage: apoptosis of primordial follicles. Chemotherapy induces double-stranded DNA breaks in the oocyte. If not repaired, they induce follicular atresia by apoptosis. Several molecules (in green), acting mainly on the different stages of the apoptotic pathway, have been proposed to avoid follicular atresia and maintain the pool of reserve follicles.

\subsection{Fertoprotective Agents}

\subsubsection{Sphingosine 1 Phosphate and Ceramide 1 Phosphate}

Sphingosine-1-phoshate (S1P) is a membrane sphingolipid involved in several physiological processes, including apoptosis of ovarian follicles. Indeed, it was shown that the sphingomyelin pathway regulates the developmental death of oocytes and S1P protects the ovarian reserve from radiation injuries [31]. Later, in an animal model, S1P injection directly into the ovaries was shown to decrease the apoptosis of primordial follicles induced by chemotherapy and thus protect fertility [32,33]. In a human ovarian xenograft model, S1P can block the human apoptotic follicle death induced by cyclophosphamide and doxorubicin and preserve the primordial follicle stockpile [34,35]. Moreover, S1P seems to reduce the atresia of primordial follicles that occurs during the slow freezing and thawing of human ovarian cortical strips, confirming its protective role [36]. Recently, ceramide 1 phosphate (C1P), another sphingolipid, was also found to be a potential ovarian protective agent as ovarian administration of this drug reduces the ovarian damage induced by cyclophosphamide and protects the ovarian reserve via the inhibition of apoptosis and improvement of stromal vasculature [37]. However, one study had conflicting results, demonstrating that S1P was not effective against apoptosis in rats after intraperitoneal cyclophosphamide treatment [38].

One of the major limitations of these treatments is that S1P and C1P must be administered by continuous administration or injection directly into the ovaries. Nevertheless, recently, a long-acting oral form of an S1P analog has been developed and its impact on the ovaries was evaluated in a rat 
model [39]. It was suggested that this treatment might decrease spontaneous follicular apoptosis, making these molecules potentially appropriate for human use.

However, even if S1P might be a promising fertility preservation strategy in the future, additional studies have to be conducted to confirm the protective role of this molecule, to evaluate possible interference with chemotherapy, and to evaluate the impact of this strategy on offspring.

\subsubsection{Imatinib}

Imatinib is a competitive tyrosine kinase inhibitor and, more specifically, a c-Abl kinase inhibitor. This protein is implicated in the apoptotic pathway induced by DNA damage in activating TAP63 transcriptional activity. Clinically, it is used for the treatment of hemopathies or other cancers. Based on its role as a c-Abl kinase inhibitor, imatinib was evaluated as a molecule to prevent the primordial follicle loss caused by cisplatin as this drug was shown to induce DNA damage and subsequent apoptosis in primordial follicles via TAP63 activation. It was hypothesized that imatinib could prevent the TAP63 accumulation and activation induced by cisplatin and thus impede follicle apoptosis. This molecule was first evaluated in 2009 by Gonfloni et al. in a mouse model [26]. In this study, the authors observed the occurrence of massive primordial and primary follicle depletion in cisplatin-treated mice, whereas they noted a significant rescue of these follicles in the ovaries of mice simultaneously treated with cisplatin and imatinib. Furthermore, they showed that this treatment had a long-term impact on fertility and reproductive outcomes. Similar results were found by the same team in 2012 [40], while others have confirmed these results using in vitro newborn ovary cultures [41] and in vitro culture and subrenal grafting of mouse ovaries [42]. Nevertheless, two studies have also contested these results, finding that imatinib did not protect primordial follicles from cisplatin-induced apoptosis and did not prevent impaired fertility $[28,43]$.

Thus, due to the existence of conflicting results, additional studies are needed to evaluate whether imatinib could be a new treatment to limit cisplatin gonadotoxicity. Moreover, as imatinib interferes with the apoptotic pathway, it will be crucial to show that imatinib does not interfere with the antitumor activity of cisplatin.

\subsubsection{Molecules Interfering with the DNA Repair Pathway}

Following spontaneously occurring, or chemotherapy-induced, DNA damage, the efficiency of the DNA repair pathway is a critical determinant of a cell's survival. Thus, several studies have tried to develop molecules aiming to induce DNA repair instead of the apoptosis pathway to encourage follicle survival and limit follicular depletion.

For example, Rad 51 is a protein implicated in DNA repair after double-strand breaks. It was shown that, in an in vitro oocyte culture model, DNA damage in oocytes can be induced by doxorubicin and that oocytes possess the machinery and capability for repairing such DNA damage through Rad51 activation [44]. So, strategies manipulating Rad51 could be potential candidates to limit follicle depletion due to chemotherapy.

Recently, Rossi et al. reported the protective effect of luteinizing hormone (LH) on the primordial follicle pool of prepubertal mouse ovaries against cisplatin-induced follicular depletion [27]. First, these authors conducted an in vitro analysis and showed that LH treatment of prepubertal ovarian fragments generated antiapoptotic signals, reducing the oocyte level of proapoptotic TAp63 protein and favoring the DNA repair pathway in the oocytes. Thereafter, they showed that the administration of a single dose of LH to prepubertal female mice, concomitantly with cisplatin injection, inhibited the depletion of the primordial follicle reserve caused by the drug. If this protective role of recombinant LH is confirmed, it could be a very interesting candidate as this molecule is already available to women. Thus, clinical studies could be conducted relatively quickly. 


\section{Follicular Activation}

\subsection{Physiopathology of Ovarian Reserve Depletion Due to Follicular Activation}

A more recent theory suggests that chemotherapy, such as cyclophosphamide or cisplatin, induces follicular depletion through the massive growth of resting follicles, occurring simultaneously with the apoptosis of growing follicles [45]. Recruitment of primordial follicles would be secondary to the activation of the PI3K signaling pathway, whose role in follicle quiescence has been well-established by many knockout mouse models as well as in vitro studies on human ovarian cortex fragments $[8,46]$. In addition, cytotoxic agents destroy growing follicles, resulting in a reduction in AMH secretion. As this hormone is supposed to inhibit primordial follicles' recruitment, its decrease amplifies follicular activation and the subsequent depletion of the follicular reserve. In the first study revealing this hypothesis, no primordial follicles showed signs of apoptosis [45]. Other studies, using the same mouse model, confirmed this hypothesis, called the "burnout effect" $[47,48]$. Thus, the burnout effect consists of the trigger of recruitment of dormant follicle growth, mediated by an upregulation in the PI3K/PTEN/Akt pathway, occurring simultaneously with large follicle apoptosis and resulting in a reduction of $\mathrm{AMH}$ secretion. The route by which chemotherapy induces the activation of this signaling pathway remains unclear. It may be via the direct influence on the oocytes and pregranulosa cells of primordial follicles [49]. This theory was also supported when using other cytotoxic agents such as cisplatin [50,51]. In consideration of this theory, Lande et al. showed that, in vitro, phosphoramide mustard, a cyclophosphamide metabolite, enhances human primordial follicle activation in developing follicles [52]. This theory could also explain the alteration of the follicular reserve induced by the presence of an ovarian endometrioma [53] or massive follicular loss secondary to ovarian cortex transplantation $[54,55]$. Nevertheless, the molecular mechanism by which chemotherapy activates the PI3K pathway within primordial follicles is not known.

In accordance with this hypothesis, in the last few years, several investigations have been carried out to develop new molecules that would preserve the ovarian reserve by inhibiting the PI3K pathway and follicular activation (Figure 2) [3,56].

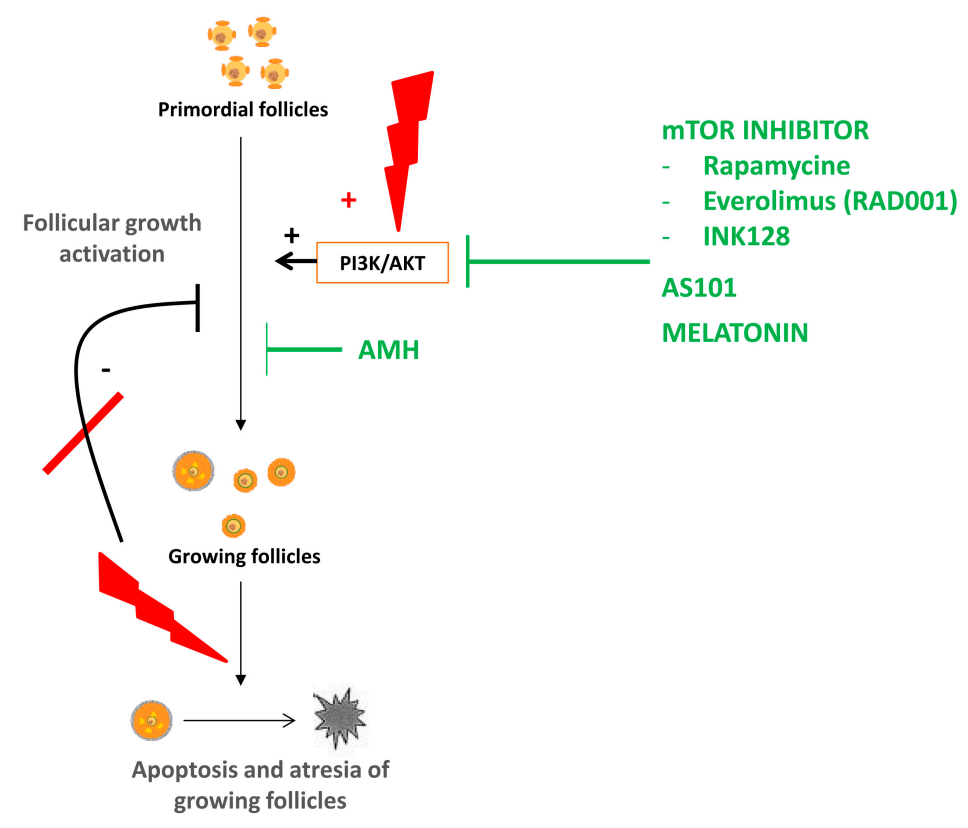

Figure 2. Second hypothesis of chemotherapy-induced ovarian damage: "burnout" effect. Chemotherapy induces both activation of the PI3K pathway and atresia of growing follicles. These two actions cause follicular depletion by massive activation of the primordial follicles. Molecules that interfere with the PI3K pathway have been developed to block the accelerated recruitment of primordial follicles (in green). (+: activates, - inhibits) 


\subsection{Fertoprotective Agents}

\subsubsection{AS101}

AS101 [ammonium trichloro(dioxoethylene-o,o')tellurate] is a nontoxic immunomodulatory compound that modulates the PI3K-Pten-Akt pathway [57]. It has been shown to reduce the negative hematologic and dermatologic side effects of chemotherapy [58]. As cyclophosphamide was found to activate the PI3K pathway, inducing primordial follicle recruitment and subsequent follicular depletion of ovarian reserve, AS101 was investigated as a treatment to prevent cyclophosphamide-induced follicle loss in a mouse model [45]. Ultimately, in vivo treatment of mice with AS101 was found to reduce the cyclophosphamide-induced depletion of primordial follicles. No increase in fetal malformation was observed in mice previously treated with AS101, indicating the safety of this treatment for offspring. This treatment was the first one tested and yielded encouraging results; nevertheless, to date, no other studies using this molecule to prevent cyclophosphamide ovarian damage have been performed.

\subsubsection{Anti-Müllerian Hormone}

AMH is a glycoprotein hormone expressed by the granulosa cells surrounding the oocytes. It is produced by follicles from the primary stage of development until selection for dominance, and plays a key role during folliculogenesis. As it has been shown to limit the activation of primordial follicles in in vivo or in vitro mouse models [59-61], it was suggested in three recent studies that this hormone could be an effective treatment option to limit chemotherapy-induced gonadotoxicity $[48,62,63]$.

Kano et al. reported that, in mice, superphysiologic doses of AMH delivered either by a recombinant protein via osmotic pumps or gene therapy could limit the primordial follicle loss induced by cyclophosphamide, doxorubicin, or cisplatin [62]. The protective effects of AMH vary between drugs, suggesting that different mechanisms for ovarian damage are induced by different chemotherapeutic agents.

Recently, we assessed the protective effect of $\mathrm{AMH}$ in pubertal mice treated with cyclophosphamide [48]. In this model, we showed that the ovaries of cyclophosphamide-treated mice were depleted of primordial follicles, whereas the number of primordial and early-growing follicles was similar to that in controls among the ovaries of mice treated with concomitant injections of cyclophosphamide and AMH. Then, we showed that 15 weeks after the end of the treatment, the number of ovulated eggs after ovarian stimulation was significantly reduced in cyclophosphamide-treated mice and rescued by AMH co-administration. The molecular mechanisms underlying these effects were explored. Interestingly, an investigation of the PI3K signaling pathway showed that the phosphorylation of FoxO3A was significantly lower in mouse ovaries treated with AMH. This transcription factor, expressed in the nucleus of primordial follicles, plays an essential role in the maintenance of primordial follicles in a quiescent state [6]. The phosphorylation of FoxO3A induces the protein nuclear export, leading to the activation of primordial follicles [8]. Our results suggested that AMH might inhibit primordial follicle recruitment by preventing cytoplasmic shuttling of FoxO3A induced by cyclophosphamide. Moreover, in this study, we also provide evidence of a possible role of autophagy in the preservation of the follicular pool reserve. Indeed, we showed that AMH administration was able to induce autophagy in ovaries and a possible mechanism to explain the modulation of AMH-induced autophagy might implicate FOXO3A as this factor was shown to be related to autophagy activation [64]. These results are in accordance with those of other studies suggesting the involvement of autophagy in the regulation of follicular ovarian reserve [13,65].

Further, Roness et al. confirmed the fertoprotective role of recombinant $\mathrm{AMH}$ in the same mouse model as pharmacological administration of AMH during chemotherapy treatment reduced follicle activation and primordial follicle loss and significantly improved reproductive outcomes [63]. Interestingly, they also showed that AMH does not interfere with the therapeutic actions of chemotherapy. 
These data indicate that $\mathrm{AMH}$ represents a potential novel treatment for limiting the primordial follicle depletion induced by chemotherapy. Nevertheless, these promising results need to be confirmed further. As AMH is produced only by the ovaries and acts through a specific receptor mainly expressed by the ovaries, this hormone might be of particular interest since it could act as a targeted therapy without interfering with physiological mechanisms or the efficacy of chemotherapy.

\subsubsection{Melatonin}

Primarily revealed as a secretory product of the pineal gland, melatonin (N-acetyl-5-methoxytryptamine) is commonly used in various biological processes such as treating insomnia. Moreover, melatonin can be used as a potential therapeutic adjuvant during chemotherapy as it has been shown to reduce some adverse effects of drugs [66]. Interestingly, melatonin is also produced in various tissues including reproductive tissues such as the ovaries and the placenta [67], and melatonin receptors are present in the oocytes and granulosa cells of various species, including humans $[68,69]$. Some studies have revealed that melatonin treatment could limit the depletion of germ cells in the gonads during chemotherapy. In rats, melatonin administration prevents cisplatin-induced testicular toxicity and reduces sperm motility [70]. Recently, it was suggested as a new fertoprotective agent option against the ovarian damage induced by chemotherapy $[51,56,71]$.

Jang et al. evaluated the protective effect of melatonin on cisplatin-treated ovaries in a mouse model [71]. They demonstrated that combined treatment with melatonin and cisplatin significantly prevented primordial follicle loss in cisplatin-treated ovaries. The molecular mechanisms implicated were also analyzed. In accordance with the burnout theory, these authors showed that the protection effect of melatonin was mediated by suppressing follicular recruitment through activation of the PI3K-Akt-FoxO3a signaling pathway. Nevertheless, this protective effect was partial. In addition, the same authors recently confirmed these results and revealed that ghrelin enhances the protective effect of melatonin against cisplatin-induced ovarian failure in a mouse model [51]. The molecular mechanisms implicated were evaluated and revealed that the coadministration of ghrelin and melatonin inhibited cisplatin-induced phosphorylation of Pten and FoxO3A. As FoxO3A phosphorylation induces its cytoplasmic translocation and subsequent follicular activation, the inhibition of this process maintains the primordial follicles in a dormant state.

This treatment seems promising, but knowledge of the details of the molecular mechanism of melatonin's protective response against chemotherapy-induced ovarian damage and the need for evaluation of this impact on ovaries requires further studies.

\subsection{4. mTOR Inhibitors}

mTOR is a serine/threonine kinase implicated in several crucial processes such as cell growth, proliferation, autophagy, and survival [72]. In mice, accelerated mTOR activity in the oocyte activates the primordial follicles, resulting in POI [73]. mTOR stimulators increase the activation of primordial follicles in animal models and mTOR inhibitors block the primordial-to-primary follicle transition [74]. According to these data, and after having confirmed the burnout theory, recent studies used, in a mouse model, mTOR inhibitors to preserve the ovarian reserve from cyclophosphamide-induced follicular depletion [75-77]. Goldman et al. explored the use of the clinically approved drug everolimus (RAD001) or the inhibition of mTORC1/2 with the experimental drug INK128, showing that mTOR inhibition preserves the ovarian reserve, as measured through primordial follicle counts and serum AMH levels [75]. Moreover, cyclophosphamide-treated mice had significantly fewer offspring, whereas cotreatment with mTOR inhibitors preserved normal fertility. The protective effect of everolimus was also demonstrated against cisplatin-induced gonadotoxicity in an in vivo mouse model [77]. As everolimus can be used in the treatment of some breast cancers, this approach represents a very interesting option for fertility preservation during conventional chemotherapy. On the other hand, Zhou et al. observed that cotreatment of chemotherapy with rapamycin, another mTOR inhibitor, prevented the follicle growth wave caused by cyclophosphamide treatment and significantly reduced 
primordial follicle loss [76]. Rapamycin is an inhibitor of the mTOR pathway, shown previously to inhibit the accelerated activation of primordial follicles of Pten-/- rat ovaries [78].

\section{Vascular Damage}

\subsection{Physiopathology}

Alterations in the ovarian stroma and vascularization are another mechanism potentially implicated in chemotherapy-induced follicle loss [3,18]. Indeed, vascular damage, revealed by decreased ovarian blood flow and reduction in ovarian size, has been demonstrated in women [79] and in mice following doxorubicin administration [80]. In addition, the histological analysis of human ovaries previously exposed to chemotherapy revealed that a thickening and hyalinization of cortical stromal blood vessels had occurred in association with the disorganization of blood vessels in the ovarian cortex and cortical fibrosis [81].

\subsection{Fertoprotective Agents}

\section{G-CSF}

In light of the vascular damage induced by chemotherapy, granulocyte colony-stimulating factor (G-CSF) was tested as a fertoprotective agent. Subsequently, it was determined that treatment with G-CSF decreased chemotherapy-induced ovarian follicle loss and extended the time to premature ovarian insufficiency in female mice treated with cyclophosphamide and busulfan [82]. Later, similar protective effects were found, as follicle counts and serum AMH levels were significantly increased in mice treated with cisplatin and G-CSF as compared with mice treated with cisplatin alone [83].

\section{Other Molecules as Candidate Fertoprotective Agents}

\subsection{GnRH Analogs}

Tested in 1995 in rhesus monkeys, gonadotropin-releasing hormone (GnRH) analogs were the first agents considered as possible chemoprotective molecules against cyclophosphamide ovarian damage [84]. Subsequent studies evaluated the possible protective effects in a rodent model with contradictory results [85-90]. In a more recent study, it was proven that ovarian damage occurred even in the absence of FSH, suggesting that the inhibition of the pituitary-gonadal axis is not involved in ovarian protection during GnRH agonist treatment [90]. Nevertheless, other mechanisms potentially implicated in this protective influence were suggested to be vascular effects or the upregulation of antiapoptotic molecules [91-93].

Several clinical studies have been performed to assess, in women, the ability of GnRH analogs to protect ovaries from chemotherapy ovarian damage. POI incidence, chemotherapy-induced amenorrhea, menses recovery, or pregnancy rates were evaluated in cancer patients who received GnRH analogs or not at the time of chemotherapy treatment. Conflicting results were reported $[92,94]$. Elsewhere, a meta-analysis of randomized clinical trials revealed diverse conclusions about the ability of GnRH analogs to preserve fertility [95-98]. Nevertheless, while clinical evidence for the efficacy of this treatment is still being debated, the safety of this strategy has already been clearly demonstrated. Thus, this treatment could be proposed for all young women requiring chemotherapy, although gamete cryopreservation should be performed, if possible, for women who want to preserve their fertility.

\subsection{Tamoxifen}

Tamoxifen is an estrogen receptor antagonist and is currently used as an adjuvant therapy for hormone-sensitive breast cancer. In a rodent model, the administration of tamoxifen significantly decreased doxorubicin- or cyclophosphamide-induced follicle loss [99]. Similar results were obtained 
in cultured rat ovaries [100]. Nevertheless, the molecular mechanisms of this protective effect during chemotherapy have not been discovered yet.

\subsection{Other Molecules}

In the past few years, several other molecules have been observed to decrease chemotherapy-induced ovarian damage in the drive to preserve fertility, including Chinese herbal medicine [101], fennel [102], sildenafil citrate [103], tocotrienol [104], genistein [105], and erythropoietin [106].

\section{Conclusions}

Improving the knowledge of the molecular mechanisms involved in chemotherapy-induced ovarian damage can lead to the development of treatments to limit follicular depletion in vivo $[3,18,56]$. The molecular mechanisms implicated in the protective role of these different agents are more or less clear. Table 1 summarizes the main fertoprotective agents that have been evaluated in a mouse model, their mechanism(s) of action, and the proposed mechanism(s) to explain ovarian protection.

Table 1. Main molecules evaluated in an in vivo rodent model to limit chemotherapy-induced follicular depletion.

\begin{tabular}{|c|c|c|c|}
\hline $\begin{array}{c}\text { Fertoprotective } \\
\text { Mechanism }\end{array}$ & \multicolumn{2}{|c|}{ Fertoprotective Agent } & References \\
\hline \multirow{4}{*}{$\begin{array}{l}\text { Inhibition of primordial } \\
\text { follicular apoptosis }\end{array}$} & $\begin{array}{l}\text { Sphingosine } 1 \text { phosphate } \\
\text { ceramide } 1 \text { phosphate }\end{array}$ & Membrane sphingolipid & {$[32-35,37,38]$} \\
\hline & Imatinib & $\begin{array}{c}\text { Competitive } \\
\text { tyrosine-kinase inhibitor } \\
\text { (c-Abl kinase inhibitor) }\end{array}$ & {$[16,26,40,42]$} \\
\hline & GNF2 & c-Abl kinase inhibitor & {$[40]$} \\
\hline & $\mathrm{LH}$ & Gonadotrophine & [27] \\
\hline \multirow{5}{*}{$\begin{array}{l}\text { Inhibition of primordial } \\
\text { follicle recruitment }\end{array}$} & AS101 & PI3K modulator & {$[45]$} \\
\hline & Melatonin & Pineal hormone & {$[51,71]$} \\
\hline & Rapamycin & mTOR inhibitor & [76] \\
\hline & $\begin{array}{l}\text { Everolimus (and } \\
\text { INK128) }\end{array}$ & $\begin{array}{l}\text { mTORC1/mTORC2 } \\
\text { inhibitor }\end{array}$ & {$[75,77]$} \\
\hline & $\mathrm{AMH}$ & Ovarian hormone & {$[48,62,63]$} \\
\hline $\begin{array}{l}\text { Several mechanisms } \\
\text { proposed (e.g., vascular } \\
\text { effect, follicular } \\
\text { recruitment inhibition) }\end{array}$ & GnRH analogs & $\begin{array}{l}\text { Inhibition of the } \\
\text { pituitary-gonadal axis }\end{array}$ & {$[85,86,88-90]$} \\
\hline Vascular effect & G-CSF & $\begin{array}{c}\text { Granulocyte } \\
\text { colony-stimulating factor }\end{array}$ & {$[82,83]$} \\
\hline $\begin{array}{c}\text { Prevention of } \\
\text { chemotherapy nuclear } \\
\text { activation }\end{array}$ & Bortezomib & Proteasome inhibitor & [30] \\
\hline
\end{tabular}

Although histological studies of human ovaries were carried out years ago to assess the impact of the disease and treatments on the gonads $[107,108]$, this type of research is more difficult to perform today due to ethical concerns. Nowadays, the assessment of the gonadotoxicity of chemotherapy is often based on organotypic or cell culture models in vitro. In vivo studies in rodents as well as models of human ovarian xenograft are also commonly used to investigate the impact of chemotherapy on primordial follicles and the potential protective role of fertoprotective agents. Moreover, the main chemotherapies used in these fundamental studies were cisplatin, cyclophosphamide, or doxorubicin. 
A recent review has been published that critically discusses the damaging effects of the most common chemotherapeutic compounds (cyclophosphamide, cisplatin, and doxorubicin) on the ovaries [109]. In clinical practice, the protocols applied incorporate a combination of several drugs. Therefore, the results obtained should be extrapolated to women, but caution should be used when interpreting the clinical relevance of such findings. Indeed, it is difficult to mimic the doses and protocols used, and ovarian physiology and responses to treatments can differ.

For these molecules to be used in clinical practice and studied in women, it is essential that they do not interfere with the therapeutic action of chemotherapy or important physiological processes. However, as apoptosis represents the main mechanism of anticancer action, apoptosis inhibitors could reduce the anticancer effect of chemotherapy. In addition, by blocking the death of oocytes with DNA alterations, some molecules could facilitate the survival of damaged germ cells and thus promote infertility, an increased risk of spontaneous miscarriages, or fetal malformations. Finally, the PI3K pathway is a ubiquitous pathway and the molecules modulating this pathway could interfere with various physiological processes.

New therapies aimed at limiting follicular loss and protecting the ovaries would be of great interest. They could be used in combination with the currently available fertility preservation techniques and administered regardless of age, pathology, or proposed treatment. Moreover, they would also prevent against hormonal deficiencies and their consequences (e.g., pubertal delay, osteoporosis). Finally, these treatments may be of particular interest to women with altered ovarian reserve parameters, in whom no fertility preservation method can be proposed.

Author Contributions: C.S. write the article; I.B., N.B. and M.G. carefully revised the manuscript.

Funding: This review received no external funding.

Conflicts of Interest: The authors declare no conflict of interest.

\section{References}

1. Donnez, J.; Dolmans, M.-M. Fertility preservation in women. N. Engl. J. Med. 2017, 377, 1657-1665. [CrossRef] [PubMed]

2. Donnez, J.; Martinez-Madrid, B.; Jadoul, P.; Van Langendonckt, A.; Demylle, D.; Dolmans, M.-M. Ovarian tissue cryopreservation and transplantation: A review. Hum. Reprod. Update 2006, 12, 519-535. [CrossRef] [PubMed]

3. Roness, H.; Kashi, O.; Meirow, D. Prevention of chemotherapy-induced ovarian damage. Fertil. Steril. 2016, 105, 20-29. [CrossRef] [PubMed]

4. Woodruff, T.K. A win-win for women's reproductive health: A nonsteroidal contraceptive and fertoprotective neoadjuvant. Proc. Natl. Acad. Sci. USA 2017, 114, 2101-2102. [CrossRef]

5. Roness, H.; Kalich-Philosoph, L.; Meirow, D. Prevention of chemotherapy-induced ovarian damage: Possible roles for hormonal and non-hormonal attenuating agents. Hum. Reprod. Update 2014, 20, 759-774. [CrossRef]

6. Reddy, P.; Zheng, W.; Liu, K. Mechanisms maintaining the dormancy and survival of mammalian primordial follicles. Trends Endocrinol. Metab. TEM 2010, 21, 96-103. [CrossRef]

7. Monniaux, D.; Clément, F.; Dalbiès-Tran, R.; Estienne, A.; Fabre, S.; Mansanet, C.; Monget, P. The ovarian reserve of primordial follicles and the dynamic reserve of antral growing follicles: What is the link? Biol. Reprod. 2014, 90, 85. [CrossRef]

8. Adhikari, D.; Liu, K. Molecular mechanisms underlying the activation of mammalian primordial follicles. Endocr. Rev. 2009, 30, 438-464. [CrossRef]

9. Hsueh, A.J.W.; Kawamura, K.; Cheng, Y.; Fauser, B.C.J.M. Intraovarian control of early folliculogenesis. Endocr. Rev. 2015, 36, 1-24. [CrossRef]

10. Zheng, W.; Nagaraju, G.; Liu, Z.; Liu, K. Functional roles of the phosphatidylinositol 3-kinases (PI3Ks) signaling in the mammalian ovary. Mol. Cell. Endocrinol. 2012, 356, 24-30. [CrossRef]

11. Gawriluk, T.R.; Hale, A.N.; Flaws, J.A.; Dillon, C.P.; Green, D.R.; Rucker, E.B. Autophagy is a cell survival program for female germ cells in the murine ovary. Reproduction 2011, 141, 759-765. [CrossRef] [PubMed] 
12. Kuma, A.; Hatano, M.; Matsui, M.; Yamamoto, A.; Nakaya, H.; Yoshimori, T.; Ohsumi, Y.; Tokuhisa, T.; Mizushima, N. The role of autophagy during the early neonatal starvation period. Nature 2004, 432, 1032-1036. [CrossRef] [PubMed]

13. Delcour, C.; Amazit, L.; Patino, L.C.; Magnin, F.; Fagart, J.; Delemer, B.; Young, J.; Laissue, P.; Binart, N.; Beau, I. ATG7 and ATG9A loss-of-function variants trigger autophagy impairment and ovarian failure. Genet. Med. 2019, 21, 930-938. [CrossRef] [PubMed]

14. De Vos, M.; Devroey, P.; Fauser, B.C.J.M. Primary ovarian insufficiency. Lancet Lond. Engl. 2010, 376, 911-921. [CrossRef]

15. Winship, A.L.; Stringer, J.M.; Liew, S.H.; Hutt, K.J. The importance of DNA repair for maintaining oocyte quality in response to anti-cancer treatments, environmental toxins and maternal ageing. Hum. Reprod. Update 2018, 24, 119-134. [CrossRef]

16. Kerr, J.B.; Hutt, K.J.; Michalak, E.M.; Cook, M.; Vandenberg, C.J.; Liew, S.H.; Bouillet, P.; Mills, A.; Scott, C.L.; Findlay, J.K.; et al. DNA damage-induced primordial follicle oocyte apoptosis and loss of fertility require TAp63-mediated induction of Puma and Noxa. Mol. Cell 2012, 48, 343-352. [CrossRef]

17. Tanaka, T.; Utsunomiya, T.; Utsunomiya, H.; Umesaki, N. Irinotecan HCl, an anticancer topoisomerase I inhibitor, frequently induces ovarian failure in premenopausal and perimenopausal women. Oncol. Rep. 2008, 19, 1123-1133. [CrossRef]

18. Bedoschi, G.; Navarro, P.A.; Oktay, K. Chemotherapy-induced damage to ovary: Mechanisms and clinical impact. Future Oncol. Lond. Engl. 2016, 12, 2333-2344. [CrossRef]

19. Arnon, J.; Meirow, D.; Lewis-Roness, H.; Ornoy, A. Genetic and teratogenic effects of cancer treatments on gametes and embryos. Hum. Reprod. Update 2001, 7, 394-403. [CrossRef]

20. Meirow, D.; Schiff, E. Appraisal of chemotherapy effects on reproductive outcome according to animal studies and clinical data. J. Natl. Cancer Inst. Monogr. 2005, 34, 21-25. [CrossRef]

21. Oktem, O.; Oktay, K. A novel ovarian xenografting model to characterize the impact of chemotherapy agents on human primordial follicle reserve. Cancer Res. 2007, 67, 10159-10162. [CrossRef]

22. Luan, Y.; Edmonds, M.E.; Woodruff, T.K.; Kim, S.-Y. Inhibitors of apoptosis protect the ovarian reserve from cyclophosphamide. J. Endocrinol. 2019, 240, 243-256. [CrossRef] [PubMed]

23. Petrillo, S.K.; Desmeules, P.; Truong, T.-Q.; Devine, P.J. Detection of DNA damage in oocytes of small ovarian follicles following phosphoramide mustard exposures of cultured rodent ovaries in vitro. Toxicol. Appl. Pharmacol. 2011, 253, 94-102. [CrossRef] [PubMed]

24. Ganesan, S.; Keating, A.F. The ovarian DNA damage repair response is induced prior to phosphoramide mustard-induced follicle depletion, and ataxia telangiectasia mutated inhibition prevents PM-induced follicle depletion. Toxicol. Appl. Pharmacol. 2016, 292, 65-74. [CrossRef] [PubMed]

25. Nguyen, Q.N.; Zerafa, N.; Liew, S.H.; Findlay, J.K.; Hickey, M.; Hutt, K.J. Cisplatin- and cyclophosphamide-induced primordial follicle depletion is caused by direct damage to oocytes. Mol. Hum. Reprod. 2019, 25, 433-444. [CrossRef] [PubMed]

26. Gonfloni, S.; Di Tella, L.; Caldarola, S.; Cannata, S.M.; Klinger, F.G.; Di Bartolomeo, C.; Mattei, M.; Candi, E.; De Felici, M.; Melino, G.; et al. Inhibition of the c-Abl-TAp63 pathway protects mouse oocytes from chemotherapy-induced death. Nat. Med. 2009, 15, 1179-1185. [CrossRef]

27. Rossi, V.; Lispi, M.; Longobardi, S.; Mattei, M.; Rella, F.D.; Salustri, A.; De Felici, M.; Klinger, F.G. LH prevents cisplatin-induced apoptosis in oocytes and preserves female fertility in mouse. Cell Death Differ. 2017, 24, 72-82. [CrossRef]

28. Bildik, G.; Acılan, C.; Sahin, G.N.; Karahuseyinoglu, S.; Oktem, O. C-Abl is not actıvated in DNA damage-induced and Tap63-mediated oocyte apoptosis in human ovary. Cell Death Dis. 2018, 9, 943. [CrossRef]

29. Soleimani, R.; Heytens, E.; Darzynkiewicz, Z.; Oktay, K. Mechanisms of chemotherapy-induced human ovarian aging: Double strand DNA breaks and microvascular compromise. Aging 2011, 3, 782-793. [CrossRef]

30. Roti Roti, E.C.; Ringelstetter, A.K.; Kropp, J.; Abbott, D.H.; Salih, S.M. Bortezomib prevents acute doxorubicin ovarian insult and follicle demise, improving the fertility window and pup birth weight in mice. PLOS ONE 2014, 9, e108174. [CrossRef]

31. Morita, Y.; Perez, G.I.; Paris, F.; Miranda, S.R.; Ehleiter, D.; Haimovitz-Friedman, A.; Fuks, Z.; Xie, Z.; Reed, J.C.; Schuchman, E.H.; et al. Oocyte apoptosis is suppressed by disruption of the acid sphingomyelinase gene or by sphingosine-1-phosphate therapy. Nat. Med. 2000, 6, 1109-1114. [CrossRef] [PubMed] 
32. Tan, S.-J.; Lee, L.-J.; Tzeng, C.-R.; Wang, C.-W.; Hsu, M.-I.; Chen, C.-H. Targeted anti-apoptosis activity for ovarian protection against chemotherapy-induced ovarian gonadotoxicity. Reprod. Biomed. Online 2014, 29, 612-620. [CrossRef] [PubMed]

33. Hancke, K.; Strauch, O.; Kissel, C.; Göbel, H.; Schäfer, W.; Denschlag, D. Sphingosine 1-phosphate protects ovaries from chemotherapy-induced damage in vivo. Fertil. Steril. 2007, 87, 172-177. [CrossRef] [PubMed]

34. Li, F.; Turan, V.; Lierman, S.; Cuvelier, C.; De Sutter, P.; Oktay, K. Sphingosine-1-phosphate prevents chemotherapy-induced human primordial follicle death. Hum. Reprod. Oxf. Engl. 2014, 29, 107-113. [CrossRef]

35. Meng, Y.; Xu, Z.; Wu, F.; Chen, W.; Xie, S.; Liu, J.; Huang, X.; Zhou, Y. Sphingosine-1-phosphate suppresses cyclophosphamide induced follicle apoptosis in human fetal ovarian xenografts in nude mice. Fertil. Steril. 2014, 102, 871-877.e3. [CrossRef]

36. Guzel, Y.; Bildik, G.; Dilege, E.; Oktem, O. Sphingosine-1-phosphate reduces atresia of primordial follicles occurring during slow-freezing and thawing of human ovarian cortical strips. Mol. Reprod. Dev. 2018, 85, 858-864. [CrossRef]

37. Pascuali, N.; Scotti, L.; Di Pietro, M.; Oubiña, G.; Bas, D.; May, M.; Gómez Muñoz, A.; Cuasnicú, P.S.; Cohen, D.J.; Tesone, M.; et al. Ceramide-1-phosphate has protective properties against cyclophosphamide-induced ovarian damage in a mice model of premature ovarian failure. Hum. Reprod. Oxf. Engl. 2018, 33, 844-859. [CrossRef]

38. Kaya, H.; Desdicioglu, R.; Sezik, M.; Ulukaya, E.; Ozkaya, O.; Yilmaztepe, A.; Demirci, M. Does sphingosine-1-phosphate have a protective effect on cyclophosphamide- and irradiation-induced ovarian damage in the rat model? Fertil. Steril. 2008, 89, 732-735. [CrossRef]

39. Mumusoglu, S.; Turan, V.; Uckan, H.; Suzer, A.; Sokmensuer, L.K.; Bozdag, G. The impact of a long-acting oral sphingosine-1-phosphate analogue on ovarian aging in a rat model. Reprod. Sci. Thousand Oaks Calif. 2018, 25, 1330-1335. [CrossRef]

40. Maiani, E.; Di Bartolomeo, C.; Klinger, F.G.; Cannata, S.M.; Bernardini, S.; Chateauvieux, S.; Mack, F.; Mattei, M.; de Felici, M.; Diederich, M.; et al. Reply to: Cisplatin-induced primordial follicle oocyte killing and loss of fertility are not prevented by imatinib. Nat. Med. 2012, 18, 1172-1174. [CrossRef]

41. Morgan, S.; Lopes, F.; Gourley, C.; Anderson, R.A.; Spears, N. Cisplatin and doxorubicin induce distinct mechanisms of ovarian follicle loss; imatinib provides selective protection only against cisplatin. PLoS ONE 2013, 8, e70117. [CrossRef] [PubMed]

42. Kim, S.-Y.; Cordeiro, M.H.; Serna, V.A.; Ebbert, K.; Butler, L.M.; Sinha, S.; Mills, A.A.; Woodruff, T.K.; Kurita, T. Rescue of platinum-damaged oocytes from programmed cell death through inactivation of the p53 family signaling network. Cell Death Differ. 2013, 20, 987-997. [CrossRef] [PubMed]

43. Kerr, J.B.; Hutt, K.J.; Cook, M.; Speed, T.P.; Strasser, A.; Findlay, J.K.; Scott, C.L. Cisplatin-induced primordial follicle oocyte killing and loss of fertility are not prevented by imatinib. Nat. Med. 2012, 18, 1170. [CrossRef] [PubMed]

44. Kujjo, L.L.; Laine, T.; Pereira, R.J.G.; Kagawa, W.; Kurumizaka, H.; Yokoyama, S.; Perez, G.I. Enhancing survival of mouse oocytes following chemotherapy or aging by targeting Bax and Rad51. PLoS ONE 2010, 5, e9204. [CrossRef] [PubMed]

45. Kalich-Philosoph, L.; Roness, H.; Carmely, A.; Fishel-Bartal, M.; Ligumsky, H.; Paglin, S.; Wolf, I.; Kanety, H.; Sredni, B.; Meirow, D. Cyclophosphamide triggers follicle activation and "burnout"; AS101 prevents follicle loss and preserves fertility. Sci. Transl. Med. 2013, 5, 185ra62. [CrossRef] [PubMed]

46. Li, J.; Kawamura, K.; Cheng, Y.; Liu, S.; Klein, C.; Liu, S.; Duan, E.-K.; Hsueh, A.J.W. Activation of dormant ovarian follicles to generate mature eggs. Proc. Natl. Acad. Sci. USA 2010, 107, 10280-10284. [CrossRef]

47. Chen, X.-Y.; Xia, H.-X.; Guan, H.-Y.; Li, B.; Zhang, W. Follicle loss and apoptosis in cyclophosphamide-treated mice: what's the matter? Int. J. Mol. Sci. 2016, 17, 836. [CrossRef]

48. Sonigo, C.; Beau, I.; Grynberg, M.; Binart, N. AMH prevents primordial ovarian follicle loss and fertility alteration in cyclophosphamide-treated mice. FASEB J. 2018, 33, 1278. [CrossRef]

49. Roness, H.; Gavish, Z.; Cohen, Y.; Meirow, D. Ovarian follicle burnout: A universal phenomenon? Cell Cycle Georget. Tex. 2013, 12, 3245-3246. [CrossRef]

50. Chang, E.M.; Lim, E.; Yoon, S.; Jeong, K.; Bae, S.; Lee, D.R.; Yoon, T.K.; Choi, Y.; Lee, W.S. Cisplatin induces overactivation of the dormant primordial follicle through PTEN/AKT/FOXO3a pathway which leads to loss of ovarian reserve in mice. PLOS ONE 2015, 10, e0144245. [CrossRef] 
51. Jang, H.; Na, Y.; Hong, K.; Lee, S.; Moon, S.; Cho, M.; Park, M.; Lee, O.-H.; Chang, E.M.; Lee, D.R.; et al. Synergistic effect of melatonin and ghrelin in preventing cisplatin-induced ovarian damage via regulation of FOXO3a phosphorylation and binding to the p27Kip1promoter in primordial follicles. J. Pineal Res. 2017, 63, e12432. [CrossRef] [PubMed]

52. Lande, Y.; Fisch, B.; Tsur, A.; Farhi, J.; Prag-Rosenberg, R.; Ben-Haroush, A.; Kessler-Icekson, G.; Zahalka, M.A.; Ludeman, S.M.; Abir, R. Short-term exposure of human ovarian follicles to cyclophosphamide metabolites seems to promote follicular activation in vitro. Reprod. Biomed. Online 2017, 34, 104-114. [CrossRef] [PubMed]

53. Kitajima, M.; Dolmans, M.-M.; Donnez, O.; Masuzaki, H.; Soares, M.; Donnez, J. Enhanced follicular recruitment and atresia in cortex derived from ovaries with endometriomas. Fertil. Steril. 2014, 101, 1031-1037. [CrossRef] [PubMed]

54. Gavish, Z.; Peer, G.; Roness, H.; Cohen, Y.; Meirow, D. Follicle activation and "burn-out" contribute to post-transplantation follicle loss in ovarian tissue grafts: The effect of graft thickness. Hum. Reprod. Oxf. Engl. 2015, 30, 1003. [CrossRef]

55. Gavish, Z.; Spector, I.; Peer, G.; Schlatt, S.; Wistuba, J.; Roness, H.; Meirow, D. Follicle activation is a significant and immediate cause of follicle loss after ovarian tissue transplantation. J. Assist. Reprod. Genet. 2018, 35, 61-69. [CrossRef]

56. Jang, H.; Hong, K.; Choi, Y. Melatonin and fertoprotective adjuvants: prevention against premature ovarian failure during chemotherapy. Int. J. Mol. Sci. 2017, 18, 1221. [CrossRef]

57. Hayun, M.; Naor, Y.; Weil, M.; Albeck, M.; Peled, A.; Don, J.; Haran-Ghera, N.; Sredni, B. The immunomodulator AS101 induces growth arrest and apoptosis in multiple myeloma: Association with the Akt/survivin pathway. Biochem. Pharmacol. 2006, 72, 1423-1431. [CrossRef]

58. Kalechman, Y.; Albeck, M.; Oron, M.; Sobelman, D.; Gurwith, M.; Horwith, G.; Kirsch, T.; Maida, B.; Sehgal, S.N.; Sredni, B. Protective and restorative role of AS101 in combination with chemotherapy. Cancer Res. 1991, 51, 1499-1503.

59. Durlinger, A.L.; Kramer, P.; Karels, B.; de Jong, F.H.; Uilenbroek, J.T.; Grootegoed, J.A.; Themmen, A.P. Control of primordial follicle recruitment by anti-Müllerian hormone in the mouse ovary. Endocrinology 1999, 140, 5789-5796. [CrossRef]

60. Durlinger, A.L.L.; Gruijters, M.J.G.; Kramer, P.; Karels, B.; Ingraham, H.A.; Nachtigal, M.W.; Uilenbroek, J.T.J.; Grootegoed, J.A.; Themmen, A.P.N. Anti-Müllerian hormone inhibits initiation of primordial follicle growth in the mouse ovary. Endocrinology 2002, 143, 1076-1084. [CrossRef]

61. Hayes, E.; Kushnir, V.; Ma, X.; Biswas, A.; Prizant, H.; Gleicher, N.; Sen, A. Intra-cellular mechanism of Anti-Müllerian hormone (AMH) in regulation of follicular development. Mol. Cell. Endocrinol. 2016, 433, 56-65. [CrossRef] [PubMed]

62. Kano, M.; Sosulski, A.E.; Zhang, L.; Saatcioglu, H.D.; Wang, D.; Nagykery, N.; Sabatini, M.E.; Gao, G.; Donahoe, P.K.; Pépin, D. AMH/MIS as a contraceptive that protects the ovarian reserve during chemotherapy. Proc. Natl. Acad. Sci. USA 2017, 114, E1688-E1697. [CrossRef] [PubMed]

63. Roness, H.; Spector, I.; Leichtmann-Bardoogo, Y.; Savino, A.M.; Dereh-Haim, S.; Meirow, D. Pharmacological administration of recombinant human $\mathrm{AMH}$ rescues ovarian reserve and preserves fertility in a mouse model of chemotherapy, without interfering with anti-tumoural effects. J. Assist. Reprod. Genet. 2019, 36, 1793-1803. [CrossRef] [PubMed]

64. Warr, M.R.; Binnewies, M.; Flach, J.; Reynaud, D.; Garg, T.; Malhotra, R.; Debnath, J.; Passegué, E. FOXO3A directs a protective autophagy program in haematopoietic stem cells. Nature 2013, 494, 323-327. [CrossRef]

65. Sun, Y.-C.; Wang, Y.-Y.; Sun, X.-F.; Cheng, S.-F.; Li, L.; Zhao, Y.; Shen, W.; Chen, H. The role of autophagy during murine primordial follicle assembly. Aging 2018, 10, 197-211. [CrossRef]

66. Mills, E.; Wu, P.; Seely, D.; Guyatt, G. Melatonin in the treatment of cancer: A systematic review of randomized controlled trials and meta-analysis. J. Pineal Res. 2005, 39, 360-366. [CrossRef]

67. Reiter, R.J.; Tan, D.-X.; Tamura, H.; Cruz, M.H.C.; Fuentes-Broto, L. Clinical relevance of melatonin in ovarian and placental physiology: A review. Gynecol. Endocrinol. Off. J. Int. Soc. Gynecol. Endocrinol. 2014, 30, 83-89. [CrossRef]

68. Lee, C.J.; Do, B.R.; Lee, Y.H.; Park, J.H.; Kim, S.J.; Kim, J.K.; Roh, S.I.; Yoon, Y.D.; Yoon, H.S. Ovarian expression of melatonin Mel(1a) receptor mRNA during mouse development. Mol. Reprod. Dev. 2001, 59, 126-132. [CrossRef] 
69. Woo, M.M.; Tai, C.J.; Kang, S.K.; Nathwani, P.S.; Pang, S.F.; Leung, P.C. Direct action of melatonin in human granulosa-luteal cells. J. Clin. Endocrinol. Metab. 2001, 86, 4789-4797. [CrossRef]

70. Ateşşahin, A.; Sahna, E.; Türk, G.; Ceribaşi, A.O.; Yilmaz, S.; Yüce, A.; Bulmuş, O. Chemoprotective effect of melatonin against cisplatin-induced testicular toxicity in rats. J. Pineal Res. 2006, 41, 21-27. [CrossRef]

71. Jang, H.; Lee, O.-H.; Lee, Y.; Yoon, H.; Chang, E.M.; Park, M.; Lee, J.-W.; Hong, K.; Kim, J.O.; Kim, N.K.; et al. Melatonin prevents cisplatin-induced primordial follicle loss via suppression of PTEN/AKT/FOXO3a pathway activation in the mouse ovary. J. Pineal Res. 2016, 60, 336-347. [CrossRef] [PubMed]

72. Wullschleger, S.; Loewith, R.; Hall, M.N. TOR signaling in growth and metabolism. Cell 2006, 124, 471-484. [CrossRef] [PubMed]

73. Adhikari, D.; Zheng, W.; Shen, Y.; Gorre, N.; Hämäläinen, T.; Cooney, A.J.; Huhtaniemi, I.; Lan, Z.-J.; Liu, K. Tsc/mTORC1 signaling in oocytes governs the quiescence and activation of primordial follicles. Hum. Mol. Genet. 2010, 19, 397-410. [CrossRef] [PubMed]

74. Sun, X.; Su, Y.; He, Y.; Zhang, J.; Liu, W.; Zhang, H.; Hou, Z.; Liu, J.; Li, J. New strategy for in vitro activation of primordial follicles with mTOR and PI3K stimulators. Cell Cycle Georget. Tex. 2015, 14, 721-731. [CrossRef] [PubMed]

75. Goldman, K.N.; Chenette, D.; Arju, R.; Duncan, F.E.; Keefe, D.L.; Grifo, J.A.; Schneider, R.J. mTORC1/2 inhibition preserves ovarian function and fertility during genotoxic chemotherapy. Proc. Natl. Acad. Sci. USA 2017, 114, 3186-3191. [CrossRef]

76. Zhou, L.; Xie, Y.; Li, S.; Liang, Y.; Qiu, Q.; Lin, H.; Zhang, Q. Rapamycin Prevents cyclophosphamide-induced Over-activation of Primordial Follicle pool through PI3K/Akt/mTOR Signaling Pathway in vivo. J. Ovarian Res. 2017, 10, 56. [CrossRef]

77. Tanaka, Y.; Kimura, F.; Zheng, L.; Kaku, S.; Takebayashi, A.; Kasahara, K.; Tsuji, S.; Murakami, T. Protective effect of a mechanistic target of rapamycin inhibitor on an in vivo model ofcisplatin-induced ovarian gonadotoxicity. Exp. Anim. 2018, 67, 493-500. [CrossRef]

78. Adhikari, D.; Risal, S.; Liu, K.; Shen, Y. Pharmacological inhibition of mTORC1 prevents over-activation of the primordial follicle pool in response to elevated PI3K signaling. PLoS ONE 2013, 8, e53810. [CrossRef]

79. Ben-Aharon, I.; Meizner, I.; Granot, T.; Uri, S.; Hasky, N.; Rizel, S.; Yerushalmi, R.; Sulkes, A.; Stemmer, S.M. Chemotherapy-induced ovarian failure as a prototype for acute vascular toxicity. Oncologist 2012, 17, 1386-1393. [CrossRef]

80. Bar-Joseph, H.; Ben-Aharon, I.; Tzabari, M.; Tsarfaty, G.; Stemmer, S.M.; Shalgi, R. In vivo bioimaging as a novel strategy to detect doxorubicin-induced damage to gonadal blood vessels. PLoS ONE 2011, 6, e23492. [CrossRef]

81. Meirow, D.; Dor, J.; Kaufman, B.; Shrim, A.; Rabinovici, J.; Schiff, E.; Raanani, H.; Levron, J.; Fridman, E. Cortical fibrosis and blood-vessels damage in human ovaries exposed to chemotherapy. Potential mechanisms of ovarian injury. Hum. Reprod. Oxf. Engl. 2007, 22, 1626-1633. [CrossRef] [PubMed]

82. Skaznik-Wikiel, M.E.; McGuire, M.M.; Sukhwani, M.; Donohue, J.; Chu, T.; Krivak, T.C.; Rajkovic, A.; Orwig, K.E. Granulocyte colony-stimulating factor with or without stem cell factor extends time to premature ovarian insufficiency in female mice treated with alkylating chemotherapy. Fertil. Steril. 2013, 99, 2045-2054.e3. [CrossRef] [PubMed]

83. Akdemir, A.; Zeybek, B.; Akman, L.; Ergenoglu, A.M.; Yeniel, A.O.; Erbas, O.; Yavasoglu, A.; Terek, M.C.; Taskiran, D. Granulocyte-colony stimulating factor decreases the extent of ovarian damage caused by cisplatin in an experimental rat model. J. Gynecol. Oncol. 2014, 25, 328-333. [CrossRef] [PubMed]

84. Ataya, K.; Rao, L.V.; Lawrence, E.; Kimmel, R. Luteinizing hormone-releasing hormone agonist inhibits cyclophosphamide-induced ovarian follicular depletion in rhesus monkeys. Biol. Reprod. 1995, 52, 365-372. [CrossRef]

85. Meirow, D.; Assad, G.; Dor, J.; Rabinovici, J. The GnRH antagonist cetrorelix reduces cyclophosphamide-induced ovarian follicular destruction in mice. Hum. Reprod. Oxf. Engl. 2004, 19, 1294-1299. [CrossRef]

86. Kishk, E.A.F.; Mohammed Ali, M.H. Effect of a gonadotropin-releasing hormone analogue on cyclophosphamide-induced ovarian toxicity in adult mice. Arch. Gynecol. Obstet. 2013, 287, 1023-1029. [CrossRef] 
87. Li, X.; Kang, X.; Deng, Q.; Cai, J.; Wang, Z. Combination of a GnRH agonist with an antagonist prevents flare-up effects and protects primordial ovarian follicles in the rat ovary from cisplatin-induced toxicity: A controlled experimental animal study. Reprod. Biol. Endocrinol. RBE 2013, 11, 16. [CrossRef]

88. Detti, L.; Uhlmann, R.A.; Zhang, J.; Diamond, M.P.; Saed, G.M.; Fletcher, N.M.; Lu, M.; Williams, L.J. Goserelin fosters bone elongation but does not prevent ovarian damage in cyclophosphamide-treated prepubertal mice. Fertil. Steril. 2014, 101, 1157-1164.e1. [CrossRef]

89. Hasky, N.; Uri-Belapolsky, S.; Goldberg, K.; Miller, I.; Grossman, H.; Stemmer, S.M.; Ben-Aharon, I.; Shalgi, R. Gonadotrophin-releasing hormone agonists for fertility preservation: Unraveling the enigma? Hum. Reprod. Oxf. Engl. 2015, 30, 1089-1101. [CrossRef]

90. Horicks, F.; Van Den Steen, G.; Gervy, C.; Clarke, H.J.; Demeestere, I. Both in vivo FSH depletion and follicular exposure to Gonadotrophin-releasing hormone analogues in vitro are not effective to prevent follicular depletion during chemotherapy in mice. Mol. Hum. Reprod. 2018, 24, 221-232. [CrossRef]

91. Blumenfeld, Z. How to preserve fertility in young women exposed to chemotherapy? The role of GnRH agonist cotreatment in addition to cryopreservation of embrya, oocytes, or ovaries. Oncologist 2007, 12, 1044-1054. [CrossRef] [PubMed]

92. Blumenfeld, Z. Fertility preservation using GnRH agonists: Rationale, possible mechanisms, and explanation of controversy. Clin. Med. Insights Reprod. Health 2019, 13, 1179558119870163. [CrossRef] [PubMed]

93. Poggio, F.; Lambertini, M.; Bighin, C.; Conte, B.; Blondeaux, E.; D’Alonzo, A.; Dellepiane, C.; Buzzatti, G.; Molinelli, C.; Boccardo, F.; et al. Potential mechanisms of ovarian protection with gonadotropin-releasing hormone agonist in breast cancer patients: A Review. Clin. Med. Insights Reprod. Health 2019, 13, 1179558119864584. [CrossRef] [PubMed]

94. Lambertini, M.; Horicks, F.; Del Mastro, L.; Partridge, A.H.; Demeestere, I. Ovarian protection with gonadotropin-releasing hormone agonists during chemotherapy in cancer patients: From biological evidence to clinical application. Cancer Treat. Rev. 2019, 72, 65-77. [CrossRef]

95. Vitek, W.S.; Shayne, M.; Hoeger, K.; Han, Y.; Messing, S.; Fung, C. Gonadotropin-releasing hormone agonists for the preservation of ovarian function among women with breast cancer who did not use tamoxifen after chemotherapy: A systematic review and meta-analysis. Fertil. Steril. 2014, 102, 808-815.e1. [CrossRef]

96. Shen, Y.-W.; Zhang, X.-M.; Lv, M.; Chen, L.; Qin, T.-J.; Wang, F.; Yang, J.; Liu, P.-J.; Yang, J. Utility of gonadotropin-releasing hormone agonists for prevention of chemotherapy-induced ovarian damage in premenopausal women with breast cancer: A systematic review and meta-analysis. OncoTargets Ther. 2015, 8, 3349-3359. [CrossRef]

97. Munhoz, R.R.; Pereira, A.A.L.; Sasse, A.D.; Hoff, P.M.; Traina, T.A.; Hudis, C.A.; Marques, R.J. Gonadotropin-releasing hormone agonists for ovarian function preservation in premenopausal women undergoing chemotherapy for early-stage breast cancer: A systematic review and meta-analysis. JAMA Oncol. 2016, 2, 65-73. [CrossRef]

98. Senra, J.C.; Roque, M.; Talim, M.C.T.; Reis, F.M.; Tavares, R.L.C. Gonadotropin-releasing hormone agonists for ovarian protection during cancer chemotherapy: Systematic review and meta-analysis. Ultrasound Obstet. Gynecol. Off. J. Int. Soc. Ultrasound Obstet. Gynecol. 2018, 51, 77-86. [CrossRef]

99. Ting, A.Y.; Petroff, B.K. Tamoxifen decreases ovarian follicular loss from experimental toxicant DMBA and chemotherapy agents cyclophosphamide and doxorubicin in the rat. J. Assist. Reprod. Genet. 2010, 27, 591-597. [CrossRef]

100. Piasecka-Srader, J.; Blanco, F.F.; Delman, D.H.; Dixon, D.A.; Geiser, J.L.; Ciereszko, R.E.; Petroff, B.K. Tamoxifen prevents apoptosis and follicle loss from cyclophosphamide in cultured rat ovaries. Biol. Reprod. 2015, 92, 132. [CrossRef]

101. Xia, T.; Fu, Y.; Gao, H.; Zhao, Z.; Zhao, L.; Han, B. Recovery of ovary function impaired by chemotherapy using Chinese herbal medicine in a rat model. Syst. Biol. Reprod. Med. 2014, 60, 293-303. [CrossRef] [PubMed]

102. Hassanpour, A.; Yousefian, S.; Askaripour, M.; Sharififar, F.; Ezzatabadipour, M. Ovarian protection in cyclophosphamide-treated mice by fennel. Toxicol. Rep. 2017, 4, 160-164. [CrossRef] [PubMed]

103. Taskin, M.I.; Yay, A.; Adali, E.; Balcioglu, E.; Inceboz, U. Protective effects of sildenafil citrate administration on cisplatin-induced ovarian damage in rats. Gynecol. Endocrinol. Off. J. Int. Soc. Gynecol. Endocrinol. 2015, 31, 272-277. [CrossRef] [PubMed] 
104. Saleh, H.S.; Omar, E.; Froemming, G.R.A.; Said, R.M. Tocotrienol preserves ovarian function in cyclophosphamide therapy. Hum. Exp. Toxicol. 2015, 34, 946-952. [CrossRef] [PubMed]

105. Saleh, D.O.; Mansour, D.F. Ovario-protective effects of genistein against cyclophosphamide toxicity in rats: Role of anti-müllerian hormone and oestradiol. Eur. J. Pharmacol. 2016, 789, 163-171. [CrossRef]

106. Sayan, C.D.; Tulmac, O.B.; Karaca, G.; Ozkan, Z.S.; Yalcin, S.; Devrim, T.; Badem, N.D. Could erythropoietin reduce the ovarian damage of cisplatin in female rats? Gynecol. Endocrinol. 2018, 34, 309-313. [CrossRef]

107. Himelstein-Braw, R.; Peters, H.; Faber, M. Morphological study of the ovaries of leukaemic children. Br. J. Cancer 1978, 38, 82-87. [CrossRef]

108. Familiari, G.; Caggiati, A.; Nottola, S.A.; Ermini, M.; Di Benedetto, M.R.; Motta, P.M. Ultrastructure of human ovarian primordial follicles after combination chemotherapy for Hodgkin's disease. Hum. Reprod. Oxf. Engl. 1993, 8, 2080-2087. [CrossRef]

109. Spears, N.; Lopes, F.; Stefansdottir, A.; Rossi, V.; De Felici, M.; Anderson, R.A.; Klinger, F.G. Ovarian damage from chemotherapy and current approaches to its protection. Hum. Reprod. Update 2019. [CrossRef]

(C) 2019 by the authors. Licensee MDPI, Basel, Switzerland. This article is an open access article distributed under the terms and conditions of the Creative Commons Attribution (CC BY) license (http://creativecommons.org/licenses/by/4.0/). 